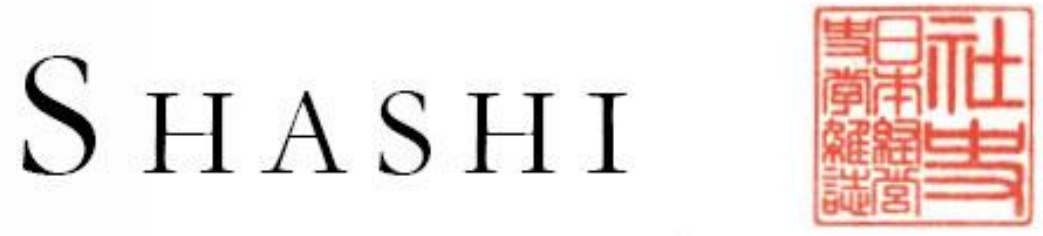

The Journal of Japanese Business and Company History

Vol. 5, No. 1 (2020) - ISSN 2169-0820 (Online) - DOI 10.5195/shashi.2020.39 a http://shashi.pitt.edu

\section{A Career of Japan: Baron Raimund von Stillfried and Early Yokohama Photography. Gartlan, Luke. Leiden-Boston: Brill, 2016. xii + 371 pp. ISBN 978-9-0042-8932-1}

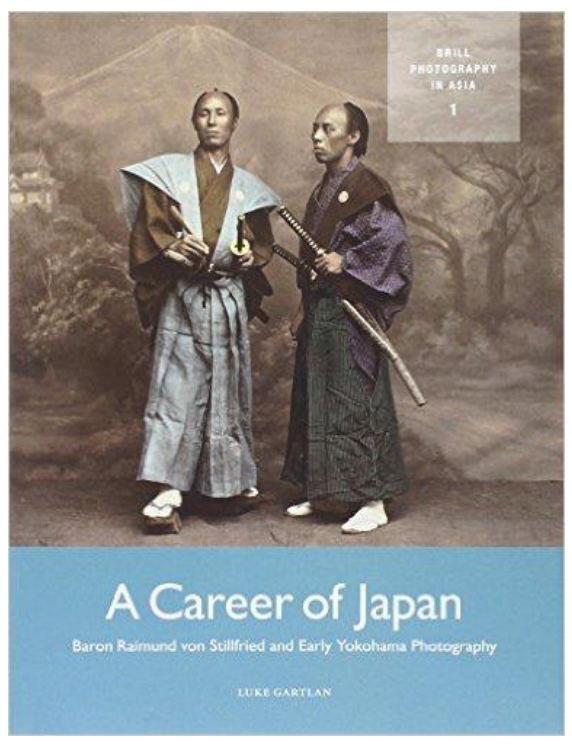

The first volume in Brill's projected series titled "Photography in Asia," A Career of Japan: Baron Raimund von Stillfried and Early Yokohama Photography is an in-depth look at Raimund von Stillfried's extraordinary life and work as an expatriate photographer who arrived in Nagasaki in 1864 and then returned to Vienna in 1883. At the same time, this volume is designed to address the dearth of critical scholarship on the Yokohama photographic industry, and the realities of foreign involvement (aesthetic and commercial) during the Meiji era, though the later would require a more thorough look at his rivals and their contributions.

The author, Luke Gartlan, $\mathrm{PhD}$, a lecturer at the School of Art History, University of St Andrews, has with this publication sought to redress major inaccuracies and omissions in the secondary literature. A noted lacuna in scholarship includes the neglect of German-speaking photographers in favor of British and French expatriates, which is rectified with this volume.

Stylistically, the author's outline remains awkwardly embedded in the text and he often reminds the reader of his intentions with the material, which is to re-situate Baron von Stillfried in the art historical canon. After a brief introduction with starts with the protagonist's death, the first of seven chapters, "From Dreams to Specters," introduces Stillfried, his schooling and formative experiences in Austria, followed by life in Imperial Mexico. Here the author situates his subject in various historical contexts- Austro-Hungarian, Habsburgian, Imperial Mexican, and ultimately nationalist Meiji culture in subsequent chapters- to better explain his career, treatment in Japan, experiences overseas, and this later reception in Austria, which is the subject of the Afterword.

Chapter 2, "Changing Views" chronicles Stillfried's early activities as a merchant and diplomatic official in Japan and ultimate emergence as a professional photographer in Yokohama" (8). The importance of Stillfried's early out-door work and of his mentors - Charles Parker, Wilhelm Burger, and Felice Beato — is more fully recognized here than in previous scholarship through the comparison of images. "Stillfried's first portfolio is both informed by the established models in Yokohama, and yet demonstrates a marked aesthetic sensibility that reflects his academic background and the changing market demands of the period" (p.31). It was during this time that .Stillfried's practice shifted from one of topographical studies (for foreign residents) to studio-based work in order to attract the attention of affluent globetrotters. The latter employed imagery that reaffirmed ideas of what constitutes the traditional versus an increasingly modern Japan reflected in everyday scenes. This transition makes fascinating fodder for 
cultural studies on the opening of Japan to Western influence, and perception-reception in a cross cultural and historical context.

In Chapter 3, "The Mikado Photograph Affair," we learn about the first of two ideas that were designed to advance the photographer's reputation and business, yet ultimately flaunted his status as an expatriate and caused sanctions again him. In January 1872, Stillfried photographed without consent or former approval, the Tenno (or Emperor) of Japan on the occasion of his visit to the arsenal in Yokohama. The aftermath caused sanctions against the photographer, but did not bar him from later governmental opportunities, and in fact forced the hand of the Japanese to adopt their own image-making strategies.

Stillfried's official commission to photograph the northern island of Hokkaido and its indigenous inhabitants, the Ainu, is the subject of Chapter 4, "Picturing Hokkaido." For the Japanese government, whose agenda included controlling their image home and aboard while unifying the country, an expatriate photographer like Stillfried was the perfect agent, and he the consummate opportunist as his fieldwork yielded two portfolios - an ethnographic study, one of the first of the Ainu, destined for the government and the other, a saleable portfolio of topographical views of Hokkaido. The complexity of sponsored versus commercial images is carefully explained by the author in dual presentations at the Vienna World Exposition.

The trials, tribulations, and exposé of character resulting from his plan to export a seven room teahouse to Europe, which Stillfried did in 1873 for the Vienna World Exposition, is thoroughly covered in chapter 5. The previously neglected public and private accounts of this commercial venture are the bases for the author's perceptive (but perhaps overreaching) conclusions. "Yokohama photography has a seamy underside, repressive, exploitative, and even violent, that belies the tranquil world usually depicted in its visual products.... Stillfried was much more than a photographer... [His] teahouse, as a commercial venture undertaken in a private capacity, is representative of the general lack of attention afforded merchants' activities, especially in comparison to the burgeoning scholarship on the official Japanese exhibits" (p.144). Gartlan's lengthy analysis of the various reviews and articles on the teahouse further reveals the contradictions between the treatment of Japanese models and the tranquility of their image in subsequent photographs. The conclusion thus that the expatriate artist (and others like him, though this is not proven) were not saints ever attempting to produce art for art sake, but rather consummate entrepreneurs for whom art (or photography) was a means to a financial end is, not a profound but, the noteworthy conclusion here. As judiciously stated, Stillfried himself was paradoxically "both a noble-born member of a respected family, [an artist], and a populist businessman" (159). The more liberal use of the word 'artist' as a descriptor would strengthen Stillfried's case for significance, even if the volumes he produced were in great quantities.

The fact that Stillfried was not solely a commercial photographer is further elucidated in Chapter 6, "A Merchant of Images." He produced photographs for European globetrotters, but also served as a guide to visiting foreigners, a merchant of cultural objects and goods, an importer of photographic equipment, and a mentor/teacher of the next generation of Japanese (and expatriate) photographers (p.8). The various names of Stillfried's businesses are here explained and delineated in Appendix C, which provides a helpful timeline of Raimund von Stillfried's studios, associates, and competitors. Takeover of the Japan Photographic Association provided a (business) platform to create a global enterprise, supported by Stillfried's practice of "sending work to overseas societies, corresponding with professional journals, and exhibiting at international expositions" (p.168). As the author aptly notes, this study requires that we think globally and not in terms of a specific local geography, because Stillfried was an "intercultural mediator" and in it for business which becomes evident as we follow the money in this story.

Stillfried's studio production is discussed in chapter 7. His work, which arguably had a profound effect on the international perception of Japan, also "reflected [the photographer's] unease with the rise of a domestic photographic industry that threatened his own professional authority and market control" (p.9). 
In Chapter 8, study of the various trials of Stillfried reveals that his colleagues Hermann Andersen and Baron Franz von Stillfried need be recognized as photographers in their own right and, by doing so, greater clarity of what can and should be attributed to Raimund becomes possible. Thereby important corrections are made to the historical record through this publication. As stated by the author, "A major aim of this study is not merely to recover Stillfried's oeuvre and the circumstances that informed its production, but to suggest possible reasons for his omission from the canon of nineteenth-century travel photographers" (p.261)

Beautifully prepared with illustrations that illuminate important points and make vital comparisons, this volume firmly establishes Raimund von Stillfried as central to the history of photography in the nineteenth century, while adding nuances and clarifications only possible through close study of archives. At the same time, this is more than a photographic monograph as it touches on a plethora of fields. Art historians and curators will wish there was a separate listing of the visual sources and their locations. Otherwise, A Career of Japan is critical to those interested in the history of cross-cultural exchange (and business), the role of the camera in visual culture (the potential of photography, and photography as art), Meiji history (and its nation building agenda), histories of travel and exploration, and Western responses to the East.

Annemarie Sawkins, PhD

Independent Curator

\section{(c) EY}

New articles in this journal are licensed under a Creative Commons Attribution 3.0 United States License.

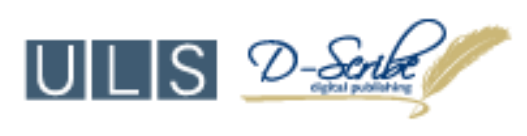

This journal is published by the University Library System, University of Pittsburgh as part of its D-Scribe Digital Publishing Program and is cosponsored by the University of Pittsburgh Press. 